\title{
Perceived Parental Support and Self-efficacy for Avoiding Sedentary Behaviors and Overweight Status among School Children
}

\author{
Melvena N. Wilson', Saleh M.M. Rahman ${ }^{2, *}$, Ivette A. Lopez ${ }^{3}$, Gabre E. Kiros ${ }^{3}$, Delores C.S. James, \\ Mark B. Dignan ${ }^{5}$ \\ ${ }^{1}$ Center for Advocacy and Research on Health Equity, Tallahassee, FL 32301 \\ ${ }^{2}$ Institute of Public Health Florida A \& M University, and College of Medicine, Florida State University, Tallahassee, FL 32307 \\ ${ }^{3}$ Institute of Public Health Florida A \& M University, Tallahassee, FL 32307 \\ ${ }^{4}$ College of Health and Human Performance, University of Florida, Gainesville, FL 32611 \\ ${ }^{5}$ Department of Internal Medicine, University of Kentucky, Lexington, KY 40504 \\ *Corresponding Author: Saleh.rahman@famu.edu
}

Copyright (C) 2014 Horizon Research Publishing All rights reserved.

\begin{abstract}
Overweight in childhood is a serious public health concern. Approximately $31 \%$ of $6-19$-year-old children in the United States are obese, overweight or at risk of overweight. The sample $(\mathrm{N}=721)$ consisted of students between the ages of 9-14 years of age enrolled in grades 4th-8th in Leon and Gadsden Counties, Florida. Using a multinomial regression model, analyses revealed that students with increased perceived self-efficacy were approximately 1.4 times more likely to be overweight than their counterparts, and those who lived in Gadsden County were 1.7 times more likely to be overweight. Those enrolled in the free/reduced lunch program were $7 \%$ less likely to be overweight than their counterparts. The purpose of this study was to explore the relationship of weight with sedentary behavior, self-efficacy in sedentary behavior avoidance, perceived parental support and socio-environmental factors among African American children. The study findings contradict much of the literature in terms of perceptions about the relationship of perceived self-efficacy and behavior and underscore the need for additional research to better understand possible differences between African American and White children.
\end{abstract}

Keywords Childhood Obesity, Self-efficacy, Sedentary Behavior; School children, Health Disparities, Parental Support, Florida

\section{Introduction}

The prevalence of childhood obesity and overweight is increasing rapidly. ${ }^{1}$ Since 1980 , obesity prevalence among children and adolescents has almost tripled ${ }^{2}$. These trends have affected all major racial and ethnic groups, regions of the country and socioeconomic strata, but the largest increases in obesity occurring among racial/ethnic minority groups ${ }^{3}$. Groups disproportionately affected include African Americans, Hispanics, American Indians and low-income adolescents ${ }^{4}$. These trends in obesity are concerning because children who are obese after the age of six are 50 percent more likely to be obese as adults, regardless of parental obesity status 5 . Among children who were overweight at ages $10-15,80$ percent were obese at age $25^{6}$. The prevalence of obesity among children ages 6-11 years increased from 6.5 percent in 1980 to 19.6 percent in 2008; among adolescents ages 12-19 it increased from five percent to 18.1 percent. $^{7}$ Among girls, the prevalence of overweight and obesity increased from $27.4 \%$ in 1980 to $32.4 \%$ in 2008 , and among boys from $28.9 \%$ to $34.8 \%{ }^{8}$.

The Institute of Medicine (IOM) Standing Committee on Childhood Obesity Prevention recommended a separate IOM committee review of factors related to overweight and obesity from birth to age five, with a focus on nutrition, sedentary behavior, and policy recommendations on obesity prevention $^{3,9}$. The Standing Committee also identified that over the past 20 years Americans reduced their physical activity and increased the amount of time they spend in sedentary pursuits; only 42 percent of children between the ages of 6 and 11 exercise for an hour or more a day for five or more days per week ${ }^{10}$. Among adolescents between ages of 12 and 19, approximately eight percent exercise $^{10}$. According to Centers for Disease Control and Prevention (CDC) review of 50 studies, physical activity is important for more than overall health: it also improves students' academic performance, including grades and standardized test scores $^{12}$.

Social and physical environment is also important, as researchers have found that children's' perceptions of safety going to and from school was associated with physical 
activity levels ${ }^{12}$. Moreover, children and adolescents living in neighborhoods with more green space were less likely to be overweight than those living environments with less green space. ${ }^{13}$ Minority children were more likely to reside in neighborhoods with safety issues and limited recreational opportunities $^{14,22,23,13}$. Treatment and prevention of childhood obesity requires multidisciplinary approaches with clear understanding of social, environmental, behavioral and psychological factors ${ }^{14}$. Home and school environmental factors can discourage physical activity by being technology focused which promotes sedentary behaviors ${ }^{10}$. Fewer than one in five high school students meet the current recommendations of 60 minutes of daily physical activity $^{6,10}$. Further, researchers estimate that adolescents now spend more than seven hours per day of screen time: watching television, DVDs, movies, using a computer or a mobile device like a cell phone or MP3 player. ${ }^{22}$

Parental support and children's self-efficacy in sedentary behavior avoidance are also related likely to be related to obesity as both factors have significant roles in promoting physical activity and preventing sedentary behavior ${ }^{14,15,16 .}$

According to the National Survey of Children's Health in Florida, 33.1 percent of children between 10-17 years of age are overweight or obese: higher that the national average (30.6 percent). The prevalence rate of overweight and obesity is more than two out of five for Florida children who are poor (43.1 percent), on public health insurance ( 40.8 percent), or black non-Hispanic (45.3 percent) ${ }^{24}$.

Self-efficacy, described as a person's evaluation of his or her ability to overcome salient barriers (e.g. lack of parental support) for a given behavior (e.g. avoiding sedentary life-style) or one's ability to perform determines whether behavior will be initiated, how much effort will be expended, and whether the effort will be sustained ${ }^{29}$, is one of the primary constructs of Social Cognitive Theory. Self-efficacy has received considerable empirical scrutiny for its mediating role in the development of physical activity behaviors in particular ${ }^{31,32}$ and predicting other health behaviors. However, nearly no study has examined self-efficacy in African American children related to avoiding sedentary behaviors and its relationship with childhood obesity or overweight

Though self-efficacy is measured in many areas, few studies have examined self-efficacy in relation to adaptive behaviors in adolescents. Sedentary behavior was found to be more prevalent among African American children compared to their white counterparts ${ }^{25}$. Perceived parental supports and its relationship with development of self-efficacy in children for avoiding of sedentary behavior is not clearly understood. Some research has found inconsistent associations between self-efficacy and quality of life for ethnic adolescents. Suldo and Shaffer state that the domain specific self-efficacy during adolescences is related to numerous psychosocial adjustments indicators ${ }^{26}$. However, few studies have examined the relationship between social factors and obesity ${ }^{27}$. According to researchers, a multilevel approach incorporating individual, interpersonal, and structural factors to understand the causes of obesity must be employed ${ }^{28}$.

The purpose of this study was to explore the associations between childhood weight and child's self-efficacy in sedentary behavior avoidance, parental support, sedentary behaviors, and other selected socio-environmental factors among African American children. This study hypothesized that perceived parental support influences adolescent self-efficacy in sedentary behavior avoidance, and would be inversely associated with child's BMI. This study also explored the relationship among self-efficacy and self-reported sedentary behavior, and hypothesized that there would be an association between perceived parental supports, self-efficacy, self-reported sedentary behavior avoidance and overweight as reported body mass index (BMI) percentile.

\section{Materials and Methods}

Data for this study was collected in classroom-administered surveys in selected public schools, in Gadsden and Leon Counties in North West Florida an urban and rural population respectively.

After receiving permission from County School Boards, a meeting was held to each school to receive consent from their principals. The schools sent home a consent form with an opt-out choice, meaning if the parent did not want their child to participant they returned the form with the child. This allowed the parents to have contact information for the researcher and FAMU Institutional Review Board that approved the study. Students completed the self-administered questionnaire at school, supervised by the principal investigator during March -April 2009. A scripted introduction to the survey was read, and the researcher was available for questions. The researcher then read aloud each question, and the corresponding answer choices. Children followed along and marked their answers on the questionnaire. The height and weight of each participating child were measured at school in a private area, by the researcher using a Taylor Body Fat Analysis and Scale (used in weight only mode). Students were not allowed to see their weights, but were given their heights, to remove any stigma or undue emotional stress about weight. 


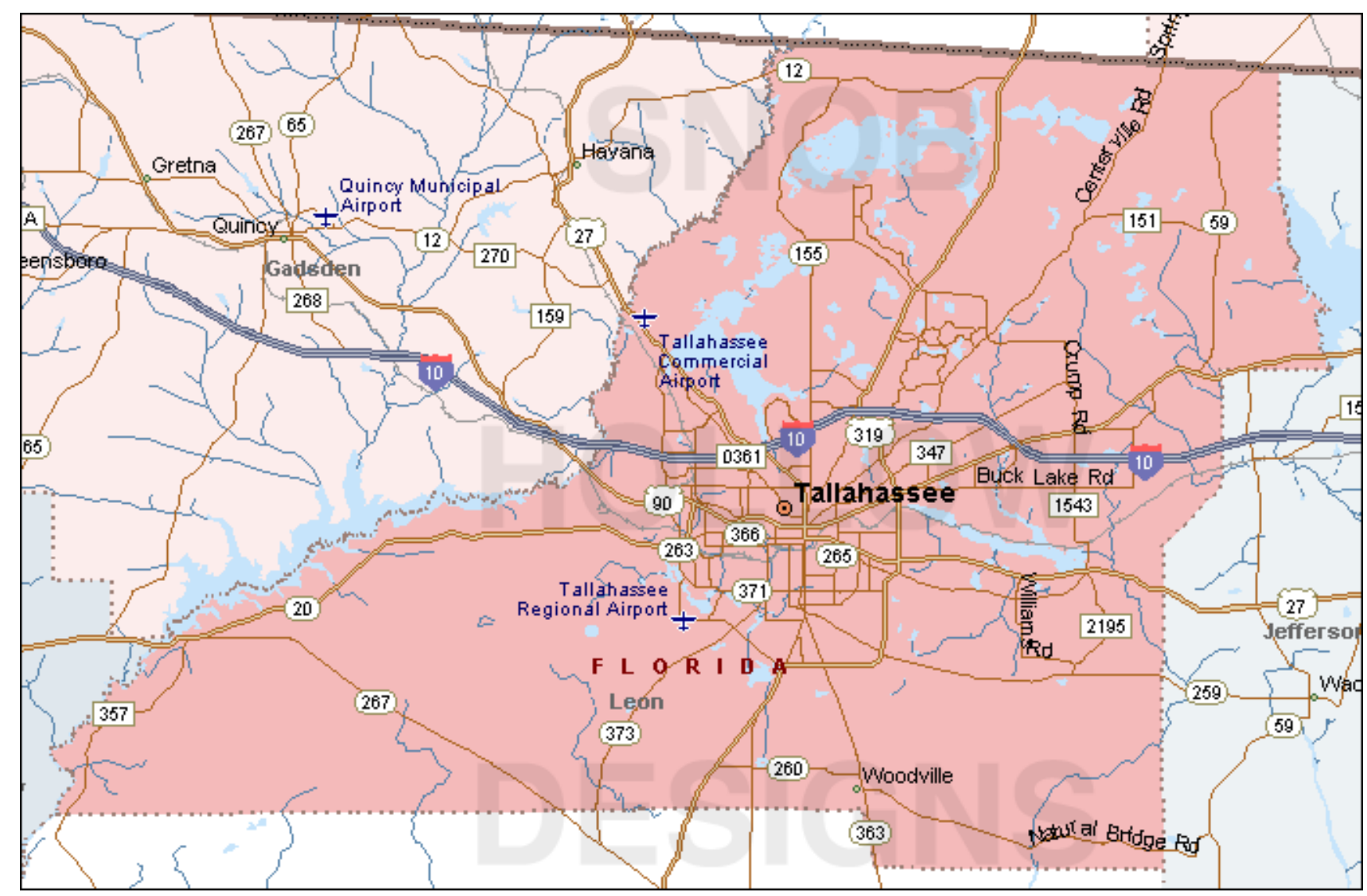

Figure 1. Map of Study Area

The sample $(\mathrm{N}=721)$ consisted of students between the ages of 9-14 years of age enrolled in grades $4^{\text {th }}-8^{\text {th }}$ Leon and Gadsden County, Florida. This age group was selected because previous research suggests that physical activity levels drop precipitously in those 13-18 years of age ${ }^{12}$.

\subsection{Instrument}

A 50-item question was developed and pilot tested based on several existing instruments. Demographic information of the children was placed at the first part of the survey. The second part of the questionnaire assessed perceptions of parental supports in addressing avoidance of sedentary behaviors, the third part dealt with measures of self-efficacy for avoiding sedentary behaviors, and the fourth half of the survey measured self-reported behaviors that elaborate avoidance of sedentary life-style.

To measure the children's self-efficacy, a modified version of the generalized self-efficacy scale developed by Schwarzer and colleagues ${ }^{33}$, and the Patient-centered Assessment and Counseling for Exercise (PACE) scale by Norman et al. ${ }^{34}$ were employed to measure self-efficacy in children to avoid sedentary behaviors. The reliability of these measures has been established, with high internal consistency, and appropriate concordance with other measures of physical activity and dietary behaviors in elementary school children ${ }^{35}$. Norman (2004) found a reliability and internal consistency of 0.81 . Another instrument, the Weight Efficacy Life-style (WEL) Questionnaire, is a 20-item instrument that consists of 5 situational factors: negative emotions, availability, social pressure, physical discomfort and positive activities. The WEL was developed by Clark and colleagues (1991) and was used as a guideline for the present study as well ${ }^{36}$. The present study questionnaire items were tailored based on the cultural appropriateness and acceptance for this study population.

Perceived parental support was assessed by an instrument with a five-point Likert scale, with responses that ranged from 1(strongly disagree) to 5 (strongly agree). In this questionnaire, several dimensions of parental supports (encouragement, providing access, direct or indirect facilitation, etc.) were measured, as those relate to avoidance of sedentary behaviors. Children's self-reported actual behaviors/time use (for avoiding sedentary life-style) were measured by asking questions developed based on Adolescents Risk Behavior Survey (YRBS), Florida Department of Health -Adolescents Physical Activity and Nutrition (YPAN) survey and a study done by Sharma ${ }^{37}$. These questions were modified depending on the cultural appropriateness and sensitivity of the question. The questionnaire was then piloted in a sample of 10 adolescents for readability before administering the final survey for data collection.

The dependent variable for this study was the children's Body Mass Index (BMI) for age and gender. The 
independent variables included: home Environment defined as perceived parental supports (access and availability of equipment and activities, modeling and encouragement), self-efficacy in avoiding sedentary behavior; self-reported sedentary behaviors, and demographics.

\subsection{Data Analysis}

The data was analyzed using SPSS 17.0 using two steps. First, descriptive statistics were performed. Second, inferential statistics and hypothesis testing were performed. Confirmatory factor analyses were conducted to measure the construct validity of scales in the instrument. Reliability coefficients were assessed to measure the internal consistency of the instrument. Pearson correlation coefficients were calculated to determine the strength of relationship between each variable. Cross-tabulation and chi-square tests were performed as preliminary bivariate analysis. A logistic regression test was used to determine the main effects for each variable and the interaction effect of the combined variables on step count totals, BMI, parental support, and self-efficacy values.

\section{Results}

Table 1 describes the demographic characteristics of the participants. Of the 721 students in the study; approximately $59 \%$ of the sample was from Leon County and $49.8 \%$ were from Gadsden County. Nearly $46 \%$ were male and $54.1 \%$ female. The mean age was 11.95 (Std. dev. $=1.52$ yrs). Of the survey respondents $69.3 \%$ of the participants were non-Hispanic African American. Approximately 14\% of participants self-identified as Hispanic, of which $37.6 \%$ were female. The majority of the study participants indicated that English was the primary language spoken at home (89\%).

Table 1. Demographics of participants and other variables

\begin{tabular}{|c|c|c|}
\hline VARIABLE & $\boldsymbol{N}$ & $\%$ \\
\hline Age & 717 & \\
\hline$\leq 9$ yrs & 37 & 5.2 \\
\hline $10-11$ yrs & 248 & 34.6 \\
\hline $12-13$ yrs & 299 & 41.7 \\
\hline$\geq 14$ yrs & 133 & 18.5 \\
\hline Grade & 720 & \\
\hline $4^{\text {th }}$ & 188 & 26.1 \\
\hline $5^{\text {th }}$ & 132 & 18.3 \\
\hline $6^{\text {th }}$ & 81 & 11.3 \\
\hline $7^{\text {th }}$ & 223 & 31.0 \\
\hline $8^{\text {th }} /$ other & 96 & 13.3 \\
\hline
\end{tabular}

\begin{tabular}{|c|c|c|}
\hline Race/Ethnicity & 721 & \\
\hline White & 72 & 10.0 \\
\hline Black & 500 & 69.3 \\
\hline Hispanic & 102 & 14.1 \\
\hline Other & 47 & 6.5 \\
\hline Lunch Program & 696 & \\
\hline Enrolled & 508 & 73.7 \\
\hline Not-enrolled & 181 & 26.3 \\
\hline Gender & 697 & \\
\hline Male & 320 & 45.9 \\
\hline Female & 377 & 54.1 \\
\hline County & 721 & \\
\hline Leon & 362 & 50.2 \\
\hline Gadsden & 359 & 49.8 \\
\hline Language spoken at home & 721 & \\
\hline English & 641 & 88.9 \\
\hline Spanish & 69 & 9.6 \\
\hline Other & 11 & 1.5 \\
\hline Weight description & 680 & \\
\hline Underweight & 68 & 10.0 \\
\hline About right & 410 & 60.3 \\
\hline Slightly Over & 176 & 25.9 \\
\hline Very Over & 26 & 3.8 \\
\hline Transportation to School & 717 & \\
\hline Walk & 71 & 9.9 \\
\hline Bike & 5 & 0.7 \\
\hline Bus & 389 & 54.3 \\
\hline Parents dropped off & 252 & 35.1 \\
\hline Transportation from School & 717 & \\
\hline Walk & 84 & 11.7 \\
\hline Bike & 4 & 0.6 \\
\hline Bus & 439 & 61.2 \\
\hline Parents picked up & 190 & 26.5 \\
\hline BMI category & 687 & \\
\hline$\leq 84^{\text {th (underweight \& normal) }}$ & 346 & 50.4 \\
\hline $85^{\text {th (overweight) }}$ & 145 & 21.1 \\
\hline $95^{\text {th } \text { (obese) }}$ & 196 & 28.5 \\
\hline
\end{tabular}


Table 2. Body Mass Index percentile among participants

\begin{tabular}{|c|c|c|c|c|c|c|}
\hline & & \multicolumn{4}{|c|}{ BMI Percentile } & \multirow[b]{2}{*}{ Total } \\
\hline & $N$ & $\begin{array}{c}\text { Underweight } \\
\left(<5^{\text {th }} \% \text { ile }\right)\end{array}$ & $\begin{array}{c}\text { Normal } \\
\left(5^{\text {th }} \% \text { ile }\right)\end{array}$ & $\begin{array}{c}\text { At Risk } \\
\left(\geq 85^{\text {th }} \% \text { ile }\right)\end{array}$ & $\begin{array}{l}\text { Overweight } \\
\left(\geq 95^{\text {thoile }}\right)\end{array}$ & \\
\hline & & & $\begin{array}{l}\text { Range: } \\
\text { 5-84.99 }\end{array}$ & $\begin{array}{l}\text { Range: } \\
85-94.99\end{array}$ & & \\
\hline Leon Males & 179 & $2.2 \%$ & $55.3 \%$ & $20.1 \%$ & $22.3 \%$ & $100 \%$ \\
\hline Leon Females & 179 & $.6 \%$ & $45.3 \%$ & $27.4 \%$ & $26.8 \%$ & $100 \%$ \\
\hline Gadsden Males & 141 & $.7 \%$ & $49.6 \%$ & $17.0 \%$ & $32.6 \%$ & $100 \%$ \\
\hline Gadsden Females & 198 & $.0 \%$ & $45.5 \%$ & $18.2 \%$ & $36.4 \%$ & $100 \%$ \\
\hline TOTALS & 697 & $.9 \%$ & $48.8 \%$ & $20.8 \%$ & $29.6 \%$ & $100 \%$ \\
\hline
\end{tabular}

\subsection{Body Mass Index Distributions}

Approximately $50 \%$ of the sample was overweight ( $>85$ th percentile) or obese ( $>95$ th percentile). When categorized into three levels, $20.1 \%$ of the study sample was overweight, and $31.9 \%$ were obese. As calculated using the CDC BMI for age and gender calculator, the rate of obesity among Leon and Gadsden adolescents is high, with $45 \%$ of the total sample being at overweight (85th percentile) and $26 \%$ of the total sample were obese (95th percentile). Approximately $39 \%$ of males were overweight and $24 \%$ were obese, respectively; in turn, $50 \%$ of females were overweight with $27 \%$ being obese. In Leon County, $41 \%$ of the overall sample was overweight and $21 \%$ were obese, compared to $48 \%$ of the Gadsden overall sample found to be overweight and $31 \%$ obese.

Table 1 describes the demographic characteristics of the participants. When analyzed by gender, the BMI distribution was as follows: $45.6 \%$ of females were normal; $22.5 \%$ and $31.8 \%$ were overweight and obese, respectively. For males, $54.4 \%$ were normal, $18.8 \%$ were overweight and $26.9 \%$ were obese. BMI distribution by race/ethnicity was as follows: $20.8 \%$ of whites were overweight and $27.8 \%$ were obese. For African Americans, the distribution was 18.8\% overweight and 31.2\% obese. Among Hispanics, 29.4\% were overweight and $34.3 \%$ were obese.

Of those students who indicated that they participated in the lunch program, approximately $29.5 \%$ were obese and $21.1 \%$ were overweight, and of those not on the program some $37.6 \%$ were obese and $19.9 \%$ were overweight.

\subsection{Environment}

Participants were asked to identify how they traveled to and from school. Approximately 10\% walked to school, with a majority either riding the bus (54.3\%) and being dropped off by a parent or guardian (35.1\%). When asked to identify their most frequent mode of transportation home from school in a separate question, $11.7 \%$ walked, $61.2 \%$ rode the bus and $26.5 \%$ were picked up from school or after-school program.
To help triangulate SES, the following two questions were asked: participation in the free/reduced lunch program (73.7\%) and residence in affordable housing (55.3\%).

\subsection{Weight Perceptions}

When asked to describe their weight $(\mathrm{N}=680), 10 \%$ of study participants self-identified as being under weight, $60.3 \%$ thought of themselves as just about the right weight, another $25.9 \%$ of adolescents saw themselves as slightly overweight and 3.8\% saw themselves as very overweight. This is a potentially important indicator of distortion in self-perception because nearly $50 \%$ of the adolescents had BMIs at or above the 85 th percentile for their age and gender.

\subsection{Sedentary Behaviors}

In this study participants were surveyed about the type of video game/electronic toys in their home. Sixty-seven percent $(67.2 \%)$ of participants indicated they had access to Nintendo, Xbox and/or play station (categorized as a sedentary game type) and $24.6 \%$ had access to Wii or interactive game access. Some $72 \%$ of the participants surveyed had a computer, cell phone and/or an MP3.

\subsection{Perceived Parental Support}

Perceived parental support (PS) and Self-Efficacy (SE) for avoiding sedentary behavior were positively correlated $(\mathrm{r}=0.56, \mathrm{p}=0.000)$. Self-efficacy and social factors $(\mathrm{SF})$ were positively correlated $(\mathrm{r}=0.31, \mathrm{p}=0.000)$. Parental support and social factors were also positively correlated $(\mathrm{r}=0.50$, $\mathrm{p}=0.000$ ). Time Use (TU) and Self-efficacy (SE) were negatively correlated $(\mathrm{r}=-0.21, \mathrm{p}=0.000)$ and time use and social factors were also weakly correlated $(\mathrm{r}=0.12, \mathrm{p}=0.000)$.

Social factors in this study include home environment (e.g. role modeling, socio-economic status (SES), etc.). Parental Support in this study includes reinforcement of dietary and physical activity, availability and accessibility, etc. Time Use in this study included how participants utilized their time after school e.g. physical activity, sedentary activities, 
and sleeping.

Table 3. Basic Descriptive Statistics and Cronbach's Alpha

\begin{tabular}{cccc}
\hline Variable & $N$ & $M$ & $\alpha$ \\
\hline Self Efficacy & 12 & 2.90 & 0.89 \\
Perceived Parental Support & 17 & 2.81 & 0.91 \\
Time Use Tech* (Self reported behaviors) & 5 & 2.45 & 0.68 \\
Social Factors (home environment) & 7 & 2.44 & 0.53 \\
Total Subscale & 47 & & 0.89 \\
\hline
\end{tabular}

*Only items that were technology based were included in this variable.

The multi-nominal logistic regression (MLR) with the reference category being normal showed: BMI at or above the 85th percentile (overweight) was for the Time Use Tech (TU) subscale with a crude odds ratio of 0.91 ( $p$-value $=0.030$; $\mathrm{CI}=0.84-0.99$ ), however the adjusted odds ratio of 0.94 (p-value $=0.201 ; \mathrm{CI}=0.86-1.03)$ did not show significance. These findings indicate that those study participants who had increased sedentary behavior were $9 \%$ less likely to be overweight compared to their normal weight counterparts. Further, SF was significant with a crude odds ratio of 0.69 ( $p$-value $=0.035 ; \mathrm{CI}=0.49-0.98)$ and an adjusted odds ratio of 0.71 (p-value $=0.134 ; \mathrm{CI}=0.46-1.11$ ). Approximately $7 \%$ of those participants who indicated low social factors were less likely to be overweight compared to their counterparts.

For those with a BMI at or above the 95th percentile (obese) the MLR showed: self-efficacy was moderately significant with an adjusted odds ratio of 1.40 (p-value $=0.045 ; \mathrm{CI}=1.01-1.94)$ and a crude odds ratio of 1.11 (p-value $=0.388 ; \quad \mathrm{CI}=0.88-1.41) . \quad$ Participants who had increased perceived self-efficacy were found to be 1.4 times more likely to be overweight than their counterparts. County of residence was also significant with an adjusted odds ratio of 1.68 (p-value $=0.022 ; \mathrm{CI}=1.08-2.61)$ and a crude odds ratio of 1.72 (p-value $=0.002 ; \mathrm{CI}=1.23-2.42$ ). Those who lived in Gadsden County were 1.7 times more likely to be overweight than their normal counterparts.

Table 4. Multinomial regression Model

\begin{tabular}{|c|c|c|c|c|}
\hline \multirow[t]{2}{*}{ VARIABLE } & \multicolumn{2}{|c|}{$\begin{array}{c}\text { BMI at risk (85th \%ile) } \\
\text { vs BMI normal }\end{array}$} & \multicolumn{2}{|c|}{$\begin{array}{c}\text { BMI over(95th \%ile) } \\
\text { vs BMI normal }\end{array}$} \\
\hline & Crude OR $(95 \% C I)$ & $\begin{array}{c}\text { Adjusted OR } \\
(95 \% \mathrm{CI}) \\
\end{array}$ & Crude OR $(95 \% \mathrm{CI})$ & $\begin{array}{c}\text { Adjusted OR } \\
(95 \% \mathrm{CI}) \\
\end{array}$ \\
\hline \multicolumn{5}{|l|}{ Subscales } \\
\hline Perceived parental support (PS) & $0.93(0.72-1.21)$ & $0.95(0.65-1.39)$ & $0.92(0.74-1.15)$ & $0.97(0.69-1.36)$ \\
\hline Self-efficacy (SE) & $1.19(0.89-1.57)$ & $1.25(0.87-1.80)$ & $1.11(0.88-1.41)$ & $1.40(1.01-1.94)^{*}$ \\
\hline Time Use (TU) & $0.91(0.84-0.99)^{*}$ & $0.94(0.86-1.03)$ & $1.02(0.95-1.10)$ & $1.02(0.94-1.11)$ \\
\hline Social Factors (SF) & $0.69(0.49-0.98)^{*}$ & $0.71(0.46-1.11)$ & $0.93(0.69-1.27)$ & $0.79(0.53-1.18)$ \\
\hline \multicolumn{5}{|l|}{ Lunch Program } \\
\hline Enrolled & $0.91(0.58-1.44)$ & $0.82(0.50-1.35)$ & $0.68(0.46-0.99)^{*}$ & $0.61(0.39-0.93)^{*}$ \\
\hline Not-enrolled & 1.00 & 1.00 & 1.00 & 1.00 \\
\hline \multicolumn{5}{|l|}{ Gender } \\
\hline Male & 1.00 & 1.00 & 1.00 & 1.00 \\
\hline Female & $1.43(0.97-2.12)$ & $1.43(0.94-2.19)$ & $1.41(1.00-2.00)^{*}$ & $1.39(1.00-2.04)$ \\
\hline \multicolumn{5}{|l|}{ County } \\
\hline Leon & 1.00 & 1.00 & 1.00 & 1.00 \\
\hline Gadsden & $0.81(.55-1.20)$ & $0.77(0.47-1.25)$ & $1.72(1.23-2.42)^{*}$ & $1.68(1.08-2.61)^{*}$ \\
\hline
\end{tabular}

NOTE: This table only contains variables that had statistically significant findings to preserve space. Full table is available via request. 
Sex (gender) was also significant at the $95^{\text {th }}$ percentile with an adjusted odds ratio of 1.39 (p-value $=0.91$; $\mathrm{CI}=0.95-2.04)$ and a crude odds ratio of 1.41 (p-value $=0.052$; $\mathrm{CI}=1.00-2.00)$. Finally, lunch program enrollment was significant with an adjusted odds ratio of 0.61 ( $\mathrm{p}$-value $=0.022 ; \mathrm{CI}=0.39-0.93$ ) and a crude odds ratio of 0.68 (p-value $=0.046 ; \quad C I=0.46-0.99) . \quad$ The model correctly predicted $50.7 \%$ of the cases, and was a significant model with a likelihood ratio of $\mathrm{p}$-value of 0.038 . However with a Cox and Snell of 0.081; Nagelkerke of 0.092. Tables outlining the crude and adjusted odds ratios for the multinomial regression variables by category are located in Table 4.

\section{Discussion}

To date, the poor predictiveness of theoretical concepts for understanding the levels of influence on healthy behavior participation among children is of substantial concern. It is not clear whether the concepts have not been appropriately applied; they are too cognitive to capture the behaviors of children, or the measures are too unreliable ${ }^{39}$. Further research with self-efficacy and children should emphasize decisions in the eating and physical activity events over which children exert the most control, and thereby, the cognitive variables could be expected to be predictive. Younger children may not exercise much control over their diet or physical activity, thus the emerging research on family focused behavioral research ${ }^{40}$. Perhaps environmental variables [e.g., parenting or availability] offer the most promise with younger children ${ }^{41}$.

The findings of this study imply that males were 1.4 times more likely than females to be overweight/obese. Those participants who had increased perceived self-efficacy were approximately 1.4 times more likely to be overweight than their counterparts, and those who lived in Gadsden County were 1.7 times more likely to be overweight. Finally, that those enrolled in the free/reduced lunch program were $7 \%$ less likely to be overweight than their normal counterparts.

The study findings also highlight the importance of possible differences among African American children and White children in perceived self-efficacy, as well as difference among urban and rural overweight.

\subsection{Limitations}

There are several limitations to this study, including limited generalizability to only those communities similar to Gadsden and Leon County, Florida. However, the study population included a rural and urban county, which adds to the usability of this dissertation data. Data was collected using a cross sectional survey, with self-reported information from adolescents ages 9-13, and the survey was administered at different times to students in different school environments which may influence the result. The survey questions were read out loud to participants and student's ability to comprehend and respond to the questions may have varied, therefore it may affect the study systematically. Finally, there was slight overlap in the survey time use Likert scale, therefore categories were collapsed. This caused a slight change in odds ratios and associations, but did not affect the associations much.

As more information becomes available, and research is translated into policy and services, children's unique needs must be addressed with messages that are easily distinguished and integrated into their daily lives. Study findings suggest that public health interventions should be multifaceted: including knowledge and skills training, and emphasizing the importance of preventing chronic diseases by addressing psycho-social factors.

\section{Conclusion}

The findings of this study do not correspond with those of existing research. However, because the instrument used in this study was newly developed and is a better assessment tool for self-efficacy, the finding of increased self-efficacy in overweight participants, may indicate that overweight children are not able to adequately adjust their avoidance of sedentary activities such as computer time, and video game use to decrease their BMI, yet are confident of their capability to be active. Because there is some interaction in the model, further research on the possible mediating and moderating effects of perceived parental support and social factors on self-efficacy should be done in the future.

These findings imply that further research with a sample that is predominantly minority need to be conducted. Given the lack of association with self-efficacy, another theoretical model may offer a better fit, including a larger focus on cultural and environmental variables.

\section{Acknowledgements}

School Boards of Leon and Gadsden Counties in Florida. Institute of Public Health, Florida A\&M University.

\section{REFERENCES}

[1] Trust for America's Health (TAHF), 2011 available at http://healthyamericans.org/obesity.

[2] CDC, 2011 Centers for Disease Center and Prevention (CDC) Behavioral Risk Factor Surveillance System Survey Data. Atlanta, Georgia: US Department of Health and Human Services, Centers for Disease Control and Prevention, 2011. Available at http://www.cdc.gov/brfss/qyestionnaire.htm.

[3] Institute of Medicine (2005). Preventing childhood obesity: Health in the balance. Washington, DC. The National Academies Press, Washington, DC. Available at http://www.nap.edu/catalog/11015.html. 
[4] Story, M. and Orleans, C.T. (2006). Building evidence for environmental and policy solutions to prevent childhood obesity: The healthy eating research program. Am J Prev Med 30(1): 96-97.

[5] Whitaker RC, Wright JA, Pepe MS, et al. "Predicting Obesity in Young Adulthood from Childhood and Parental Obesity." New England Journal of Medicine,337(13): 869-73, 1997.

[6] Centers for Disease Control and Prevention. (2009). Overweight and Obesity. Consequences. Retrieved February 27, 2009 from

http://www.cdc.gov/NCCDPHP/DNPA/obesity/childh ood/consequences.htm).

[7] Ogden, C. L., Carroll, M. D., \& Flegal, K. M. (2008). High body mass index for age among US children and adolescents, 2003-2006. JAMA, 299(20), 2401-2405.)

[8] Ogden CL, Carroll MD, Curtin LR, Lamb MM and Flegel KM . (2010) Prevalence of High Body Mass Index in US Children and Adolescents, 2007-2008. Journal of the American Medical Association. 303(3): 242-249.

[9] IOM Brief Report, 2011 Institute of Medicine, Preventing Childhood Obesity.

[10] Troiano, R.P., Berrigan, D., Dodd, K.W., Masse, L.C., Tilert, T., \& McDowell, M. (2008). Physical activity in the United States measured by accelerometer. Med Sci Sports Exer.;40:181-188.

[11] Slater SJ, Ewing R, Powell LM, et al. (2010) "The Association Between Community Physical Activity Settings and Adolescents Physical Activity, Obesity, and Body Mass Index." The Journal of Adolescent Health 47, 5: 496-503.

[12] Evenson, K.R., Birnbaum, A.S., Bedimo-Rung, A.L., Sallis, J.F.,Voorhees, C.C., Ring, K. and Elder, J.P. (2006). Girls' perception of physical environmental factors and transportation: reliability and association with physical activity and active transport to school. International Journal of Behavioral Nutrition and Physical Activity, 3:28

[13] Bell JF, Wilson JS, and Liu GC. "Neighborhood Greenness and 2-Year Changes in Body Mass Index of Children and Adolescents." American Journal of Preventive Medicine, 35(6): 547-553, 2008.

[14] Bauer, K. W., Nelson, M. C., Boutelle, K. N., \& Neumark-Sztainer, D. (2008, February 26).Parental influences on adolescents' physical activity and sedentary behavior: Longitudinal findings from Project EAT-II. International Journal of Behavioral Nutrition and Physical Activity, 5(12)

[15] Beets, M. W., Vogel, R., Chapman, S., Pitetti, K. H., \& Cardinal, B. J. (2007). Parent's social support for children's outdoor physical activity: Do weekdays and weekends matter? SexRoles, 56(1-2), 125-131.

[16] Crawford, P. B., Gosliner, W., Anderson, C., Strode, P., Becerra-Jones, Y., Samuels, S., et al.(2004). Counseling Latino mothers of preschool children about weight issues: Suggestions for a new framework. Journal of the American Dietetic Association, 104, 387-394.

[17] Centers for Disease Control and Prevention. Behavioral Risk Factor Surveillance System survey codebook.Available at: http://www.cdc.gov/BRFSS/technicalinfodata/surveydata/20 08.htm. Accessed July 19
[18] Questionnaires, datasets, and related documentation National Health and Nutrition Examination Survey 2009 http://www.cdc.gov/nchs/nhanes/nhanes_questionnaires.htm. Accessed December 17, 2009.

[19] Magarey, A.M., Daniels, L.A., Boulton, T.J., \& Cockington, R.A. (2003). Predicting obesity in early adulthood from childhood and parental obesity. Int $\mathrm{J}$ Obes Relat Metab Disord 27:505-513.

[20] U.S. Centers for Disease Control and Prevention. Adolescents Risk Behavior Surveillance - United States, 2009.

[21] US Department of Health and Human Services. The Surgeon General's Vision for a Healthy and Fit Nation, Rockville, MD.: US Department of Health and Human Services, Office of the Surgeon General January, 2010.

[22] Taveras E.M., Gillman M.W., Kleinman K., et al.(2010).Racial/Ethnic differences in early-life risk factors for childhood obesity. Pediatrics, 125(4), 686-695.

[23] Van der Horst, K., Paw, M.J., Twisk, J.W., Van Mechelen, W. (2007). A brief review on correlates of physical activity and sedentariness in adolescents. Medicine and Science in Sports and Exercise, 39, 1241-50.

[24] National Survey of Children's Health, 2007. Overweight and Physical Activity Among Children: A Portrait of States and the Nation 2009, Health Resources and Services Administration, Maternal and Child Health Bureau. http://www.cdc.gov/nchs/slaits/nsch.htm (accessed May 24, 2011).

[25] Florida CHARTS, 2009. County Profiles available at http://www.floridacharts.com

[26] Suldo, S.M. \& Shaffer, E.J. (2007). Evaluation of the Self-Efficacy Questionnaire for Children in two samples of American Adolescents. Journal of Psychoeducational Assessment; 25(4):341-355.

[27] Ball, K., Mishra, G.D., \& Crawford, D. (2003). Social factors and obesity: an investigation of the role of health behaviors. International Journal of Obesity; 27(3): 394-403.

[28] Kumanyika, S., \& Grier, S. (2006). Targeting interventions for ethnic minority and low- income populations. Future Child;16:187-207.

[29] Bandura, A. (1977). Self-efficacy: Toward a unifying theory of behavioral change. Psychological Review; 84, 191-215.

[30] Bandura, A. (1989). Regulation of Cognitive Processes through Perceived Self-Efficacy. Developmental Psychology; 25(5): 729-735.

[31] Motl, R.W., Dishman, R. K., Saunders, R. P., Dowda, M., \& Pate, R.R. (2006). Perceptions of Physical and Social Environment Variables and Self-Efficacy as Correlates of Self-Reported Physical Activity Among Adolescent Girls. Journal of Pediatric Psychology; 32(1): 6-12.

[32] Haggar MS, Chetzisarantis NLD, Biddle SJH (2002). A metaanalytic review of the theories of reasoned action and planned behavior in physical activity: predictive validity and the contribution of additional variables. J Sport Exerc Psychol. 2002;24:3-32.

[33] Schwarzer, R. and Jerusalem, M. (1995). Generalized Self-Efficacy Scale. In: Weinman, J, S Wright, and M Johnson (eds.) Measures in health psychology: A user's 
portfolio, Causal and control beliefs. pp. 35-37, Windsor England: NFER-NELSON.

[34] Norman, G.J., Vaughn, A.A., Roesch, S.C., Sallis, J.F., Calfas, K.J. and Patrick, K. (2004). Development of decisional balance and Self-efficacy measures for adolescent sedentary behaviors. Psychology and Health; 19(5):561-575.

[35] Lohaus, A., Klein-Hessling, J., Ball, J., Wild M. (2004). The prediction of health-related behavior in elementary school children. Journal of Health Psychology, 9(3):375-379.

[36] Clark, M.M., Abrams, D.B., Niaura, R.S., Eaton, C.A. and Rossi, J.S. (1991). Self-efficacy in weight management. $J$ Consult Clin Psychol.;59:739-44.

[37] Sharma, M., Wagner, D. I. \& Wilkerson, J. (2006). Predicting
Childhood Obesity Prevention Behaviors using Social Cognitive Theory. International Quarterly of Community Health Education; 24(3):191 -203.

[38] Barlow, S.E.(2007). Expert Committee Recommendations Regarding the Prevention, Assessment, and Treatment of Child and Adolescent Overweight and Obesity: Summary Report. Pediatrics 120, suppl 4 ; S164-S192.

[39] Baranowski T, Cullen K, Baranowski J. (1999). Psychosocial correlates of dietary intake. Ann Rev Nutr. 1;19:17-40.

[40] Cullen KW, Rittenberry L, Olvera N, Baranowski T. (2000). Social-environmental influences on children"s diets: results from focus groups with African-, Euro-, and Hispanic-American children and their parents. Health Educ Res. ;15: 581-90. 